\title{
COMPARISON OF I-GEL AND PROSEAL LARYNGEAL MASK AIRWAY FOR AIRWAY MANAGEMENT IN ADULT PATIENTS UNDERGOING ELECTIVE SURGERIES IN GENERAL ANAESTHESIA
}

\author{
Meghana Srivastava1, Madhavi Santpur², Isha Gupta ${ }^{3}$, Karishma Bansal $^{4}$, J. R. Thakur ${ }^{5}$, Swati Kanchan ${ }^{6}$
}

${ }^{1}$ Assistant Professor, Department of Anaesthesia, M. M. Institute of Medical Sciences and Research, Mullana, Haryana.

${ }^{2}$ Associate Professor, Department of Anaesthesia, M. M. Institute of Medical Sciences and Research, Mullana, Haryana.

${ }^{3}$ Postgraduate Student, Department of Anaesthesia, M. M. Institute of Medical Sciences and Research, Mullana, Haryana.

${ }^{4}$ Postgraduate Student, Department of Anaesthesia, M. M. Institute of Medical Sciences and Research, Mullana, Haryana.

5 Professor and HOD, Department of Anaesthesia, M. M. Institute of Medical Sciences and Research, Mullana, Haryana.

${ }^{6}$ Postgraduate Student, Department of Anaesthesia, M. M. Institute of Medical Sciences and Research, Mullana, Haryana.

\section{ABSTRACT}

\section{BACKGROUND}

Supraglottic airway devices have emerged for effective airway management requiring minimal skill as an alternative to tracheal intubation during general anaesthesia. Of these devices, ProSeal LMA has been used commonly and I-gel is novel. ProSeal LMA has an inflatable cuff forming low-pressure seal around laryngeal inlet, while I-gel is a device made of thermoplastic elastomer which is soft, gel-like and transparent with no inflatable cuff.

The present study aims to compare these two devices in terms of ease of insertion, insertion attempts, insertion time and quality of airway as primary outcome. Haemodynamic parameters and complications were observed as secondary outcome of the study.

Design- Randomised controlled trial.

\section{MATERIALS AND METHODS}

100 ASA Grade I and II patients of 18 - 60 years, scheduled for elective surgical procedures under general anaesthesia were randomly divided into two groups. In Group I $(n=50)$ ProSeal LMA was used and in Group II ( $n=50)$ I-gel was used to secure airway under general anaesthesia. Both the devices were compared in relation to number of attempts, insertion time, ease of insertion and quality of airway.

\section{RESULTS}

The success rate for placement of device $(p=0.023)$ at first attempt was higher with Group II. The mean time of insertion was 16.6 \pm 4.3 and $14.3 \pm 3.2$ seconds in Group I and II respectively $(p=0.004)$. Ease of insertion was more in Group II ( $p=0.046)$. The quality of airway was good with both the devices and was comparable.

\section{CONCLUSION}

Although I-gel and ProSeal LMA were comparable for airway management, I-gel was more easily inserted in lesser time.

\section{KEYWORDS}

ProSeal, I-gel, Laryngeal Mask Airway, Airway Management.

HOW TO CITE THIS ARTICLE: Srivastava M, Santpur M, Gupta I, et al. Comparison of I-gel and ProSeal laryngeal mask airway for airway management in adult patients undergoing elective surgeries in general anaesthesia. J. Evolution Med. Dent. Sci. 2017;6(52): 3975-3978, DOI: $10.14260 / \mathrm{Jemds} / 2017 / 860$

\section{BACKGROUND}

Airway related problem is the most common cause of morbidity and mortality associated with anaesthesia. ${ }^{1}$ Tracheal intubation remains the gold standard for maintaining a patent airway. ${ }^{2}$ Since laryngoscopy and intubation requires skill and controlled hospital environment, Supraglottic Airway Devices (SADs) have emerged as an alternative for effective airway management.

The ProSeal Laryngeal Mask Airway (PLMA); Intavent Orthofix, Maidenhead, UK), was introduced in 2000. The main modifications were a posterior extension of the mask cuff and

Financial or Other, Competing Interest: None.

Submission 25-05-2017, Peer Review 18-06-2017,

Acceptance 24-06-2017, Published 29-06-2017.

Corresponding Author:

Meghana Srivastava,

Assistant Professor,

Department of Anaesthesia,

M. M. Institute of Medical Sciences and Research,

Mullana, Haryana.

E-mail: meghana.srivastava.18@gmail.com

DOI: $10.14260 /$ jemds $/ 2017 / 860$ a Drainage Tube (DT) exiting at the mask tip. Oropharyngeal leak pressure of around $30 \mathrm{~cm}$ of water could be achieved, allowing ventilation with higher tidal volumes and airway pressures. The DT provided a reliable separation of respiratory and gastrointestinal tract, reducing the risk of aspiration in cases of regurgitation. ${ }^{3}$ It has been used for laparoscopic and abdominal surgeries in obese patients for management of anticipated difficult airway and after failed intubation. Hence, the PLMA is a welcome addition to the airway armory and is likely to increase the safety margin when it is used for controlled ventilation. ${ }^{4}$ However, the cuff needs to be inflated to create a seal around the perilaryngeal tissues. This has the potential to cause tissue distortion, venous compression and nerve injury. ${ }^{5}$

The I-gel supraglottic device (Intersurgical Ltd., Wokingham, UK) was developed in 2007 to overcome the limitations of PLMA. The mask of the I-gel is designed anatomically to fit the perilaryngeal and hypopharyngeal structures without the use of an inflatable cuff. Hence, it has potential advantages including easier insertion, minimal risk of tissue compression, and stability after insertion. ${ }^{6}$ 
This study was planned to compare the efficacy of PLMA with I-gel in adult patients posted for elective surgeries under general anaesthesia. It was hypothesised that I-gel is a superior device.

\section{Aims and Objectives}

1. To study the efficacy of PLMA and I-gel in adult patients posted for elective surgeries under general anaesthesia.

2. To observe haemodynamic changes while insertion of device and associated complications.

\section{MATERIALS AND METHODS}

The randomised controlled trial study was conducted in Department of Anaesthesiology, Maharishi Markandeshwar Institute of Medical Sciences and Research, Mullana, from September 2014 to September 2016. After obtaining approval from the Institutional Ethics Committee, 100 healthy patients with the following inclusion criteria were selected for the study.

\section{Inclusion Criteria}

1. ASA Grade I and II patients.

2. 18 - 60 years of age.

3. Mallampati score I and II as per airway assessment.

4. Undergoing elective surgery in general anaesthesia.

\section{Exclusion Criteria}

1. Cardiac, hepatic or renal diseases.

2. Pregnant patients.

3. Obese patient (BMI $\left.>25 \mathrm{~kg} / \mathrm{m}^{2}\right)$.

4. Mouth opening $<2.5 \mathrm{~cm}$.

The study population was randomly allocated to Group I $(n=50 ;$ PLMA) or Group II ( $n=50$; I-gel), using coded sealed envelope method. After obtaining a written informed consent, a thorough pre-anaesthetic evaluation was done. All necessary routine investigations were carried out. Patients were asked to fast overnight. The patient was pre-medicated with tablet alprazolam $0.25 \mathrm{mg}$ and tablet ranitidine $150 \mathrm{mg}$ orally at bed time the previous night and again 2 hours prior to surgery with 1 - 2 sips of water. An Intravenous (IV) line was secured with $18 \mathrm{G}$ cannula and fluid was started; IV glycopyrrolate $0.2 \mathrm{mg}$, midazolam $2 \mathrm{mg}$ and fentanyl 1 $\mathrm{mcg} / \mathrm{kg}$ was administered after pre-oxygenation. Baseline parameters- peripheral oxygen saturation $\left(\mathrm{SpO}_{2}\right)$, heart rate (HR), systolic (SBP), diastolic (DBP) and mean blood pressure (MAP) were noted. Anaesthesia was induced with IV propofol $2.5 \mathrm{mg} / \mathrm{kg}$ and IV rocuronium $0.5 \mathrm{mg} / \mathrm{kg}$. Appropriate size of PLMA or I-gel was inserted after 90 seconds as per group allocation of the patient. After lubricating the posterior aspect of the cuff in PLMA group, index finger technique and in I-gel group standard recommended insertion technique was followed. After placement of device, in case of PLMA the cuff was inflated. The PLMA or I-gel was then connected to the circle system of anaesthesia machine and manual ventilation was started. The position of the device was confirmed by capnography, bilateral chest movements and auscultation. Following parameters were observed; insertion time (Time from picking up the device and obtaining an effective airway), number of attempts, ease of insertion and quality of airway. In the event of partial or complete airway obstruction or a significant air leak, the device was removed and reinsertion attempted. A maximum of three insertion attempts were allowed before the device was considered a failure. An alternative device such as Endotracheal Tube (ETT) was used in such situation.

If the device was placed without resistance and no manoeuvre was required, it was graded as 'very easy'; if the device was placed with the aid of single manoeuvre (head hyperextension, mask rotation, finger manipulation) it was graded as 'easy' and when there was resistance to insertion or more than one manoeuvre was required it was graded as 'difficult.' The quality of the initial airway was assessed by leak at Peak Airway Pressure (PIP) of $20 \mathrm{~cm} \mathrm{H}_{2} \mathrm{O}$ as: Excellent $=$ No audible leak; Good $=$ An audible leak with relevant loss of air but sufficient ventilation as indicated by an $\mathrm{EtCO}_{2}<40 \mathrm{mmHg}$; and Poor= Clinically relevant loss of air and insufficient ventilation requiring repositioning or replacement of the device. Air entry into the stomach and abnormal airway sounds over the larynx was noted by auscultation.

Anaesthesia was maintained by nitrous oxide: oxygen mixture (60:40), isoflurane $(0.5-0.8 \%)$ and intermittent boluses of IV atracurium $(0.1 \mathrm{mg} / \mathrm{kg})$ was administered. The $\mathrm{HR}, \mathrm{SBP}, \mathrm{DBP}, \mathrm{MAP}, \mathrm{SpO}_{2}$ and $\mathrm{EtCO}_{2}$ and ECG changes were noted before induction at the time of PLMA/I-gel insertion, 2 and 5 minutes after insertion and after removal of device. Following events were documented: device failure, intraoperative displacement, gastric insufflation, regurgitation/aspiration, laryngospasm, bronchospasm and airway obstruction. After the completion of procedure, neuromuscular block was reversed. Device was removed once the patient was fully awake. As a complication blood staining of the device, tongue-lip-dental trauma, hoarseness of voice and presence of sore throat was observed.

\section{Statistical Methods}

The sample size for the study was calculated from the formula provided by Training for Clinical Research Program at University of California and San Francisco (UCSF; website: www.sample-size.net). Based on previous similar study ${ }^{7}$ done, the expected proportion of success in first attempt of insertion of device was determined $\left(\mathrm{P}_{0}=0.825\right.$ and $\left.\mathrm{P}_{1}=0.99\right)$. The sample size was calculated with $\alpha$-error of 0.05 and power of study $80 \%$.

For qualitative data, Chi-square test ( $\mathrm{f}>5$ ) and Fisher's exact test $(\mathrm{f}<5$ ) was applied. Demographics was compared by mean and percentage. Quantitative data was compared by Student's t-test. The p-value $<0.05$ was considered as significant. Software was used to analyse and compute data with SPSS version 20 .

\section{RESULTS}

The demographic parameters of the study population observed as age, sex, BMI score, ASA grade and Mallampati airway score were comparable in Group I and Group II.

\begin{tabular}{|c|c|c|c|c|c|c|}
\hline \multirow{2}{*}{$\begin{array}{l}\text { Insertion } \\
\text { Attempts }\end{array}$} & \multirow{2}{*}{$\mathbf{N}$} & \multicolumn{2}{|c|}{$\begin{array}{c}\text { Group I } \\
(\mathbf{n = 5 0 )}\end{array}$} & \multicolumn{2}{c|}{$\begin{array}{c}\text { Group II } \\
(\mathbf{n = 5 0 )}\end{array}$} & \multirow{2}{*}{ P-value } \\
\cline { 3 - 6 } & & $\mathbf{f}$ & $\mathbf{\%}$ & $\mathbf{f}$ & $\mathbf{\%}$ & \\
\hline 1 & 74 & 32 & 64.0 & 42 & 84.0 & \multirow{2}{*}{0.023} \\
\hline 2 & 26 & 18 & 36.0 & 8 & 16.0 & \\
\hline 3 & 0 & 0 & 0.0 & 0 & 0.0 & \multirow{2}{*}{5} \\
\hline Total & 100 & 50 & 100 & 50 & 100 & \\
\hline \multicolumn{6}{|c|}{ Table I. Number of Insertion Attempts } \\
\hline
\end{tabular}


As shown in Table I, the difference in the number of attempts between the two groups was found to be statistically significant $(p=0.023)$. The success rate for placement at first attempt was higher in Group II.

\begin{tabular}{|c|c|c|c|}
\hline Group & $\mathbf{N}$ & Mean \pm SD & P-value \\
\hline I & 50 & $16.6 \pm 4.3$ & \multirow{2}{*}{0.004} \\
\hline II & 50 & $14.3 \pm 3.2$ & \\
\hline Total & $\mathbf{1 0 0}$ & & \\
\hline \multicolumn{4}{|c|}{ Table II. Insertion Time of Device in Seconds } \\
\hline
\end{tabular}

Table II depicts the mean duration of insertion was shorter for Group II device and this was statistically highly significant $(p=0.004)$.

\begin{tabular}{|c|c|c|c|c|c|c|}
\hline \multirow{2}{*}{$\begin{array}{c}\text { Ease of } \\
\text { Insertion }\end{array}$} & \multirow{2}{*}{$\mathbf{N}$} & \multicolumn{2}{|c|}{$\begin{array}{c}\text { Group I } \\
\text { (n=50) }\end{array}$} & \multicolumn{2}{c|}{$\begin{array}{c}\text { Group II } \\
\text { (n=5) }\end{array}$} & \multirow{2}{*}{ P-value } \\
\cline { 3 - 6 } & & $\mathbf{f}$ & $\mathbf{9}$ & $\mathbf{f}$ & $\mathbf{\%}$ & \\
\hline Very Easy & 80 & 35 & 70.0 & 45 & 90.0 & \multirow{2}{*}{0.046} \\
\hline Easy & 14 & 11 & 22.0 & 3 & 6.0 & \\
\hline Difficult & 6 & 4 & 8.0 & 2 & 4.0 & \\
\hline Total & $\mathbf{1 0 0}$ & $\mathbf{5 0}$ & $\mathbf{1 0 0}$ & $\mathbf{5 0}$ & $\mathbf{1 0 0}$ & \\
\hline \multicolumn{6}{|c|}{ Table III. Ease of Insertion } \\
\hline
\end{tabular}

As shown in Table III, I-gel was easier to insert without any resistance and manoeuvre ( $\mathrm{p}=0.046)$.

\begin{tabular}{|c|c|c|c|c|c|c|}
\hline \multirow{2}{*}{$\begin{array}{c}\text { Quality of } \\
\text { Airway }\end{array}$} & \multirow{2}{*}{$\mathbf{N}$} & \multicolumn{2}{|c|}{$\begin{array}{c}\text { Group I } \\
(\mathbf{n = 5 0 )}\end{array}$} & \multicolumn{2}{c|}{$\begin{array}{c}\text { Group II } \\
(\mathbf{n = 5 0 )}\end{array}$} & \multirow{2}{*}{ P-value } \\
\cline { 2 - 6 } & & $\mathbf{F}$ & $\mathbf{\%}$ & $\mathbf{F}$ & $\mathbf{\%}$ & \\
\hline Excellent & 80 & 38 & 76.0 & 42 & 84.0 & \multirow{2}{*}{0.317} \\
\hline Good & 20 & 12 & 24.0 & 8 & 16.0 & \\
\hline Poor & 0 & 0 & 0.0 & 0 & 0.0 & \\
\hline Total & $\mathbf{1 0 0}$ & $\mathbf{5 0}$ & $\mathbf{1 0 0}$ & $\mathbf{5 0}$ & $\mathbf{1 0 0}$ & \\
\hline \multicolumn{6}{|c|}{ Table IV. Quality of Airway } \\
\hline
\end{tabular}

As shown in Table IV, the quality of airway was good with no significant difference in both the groups ( $p=0.317$ ).

\begin{tabular}{|c|c|c|c|c|}
\hline \multirow[b]{2}{*}{ Time } & \multicolumn{2}{|l|}{ HR } & \multicolumn{2}{|l|}{ MAP } \\
\hline & Group & P-value & Group & $\begin{array}{c}\text { P- } \\
\text { value }\end{array}$ \\
\hline \multirow{2}{*}{$\begin{array}{c}\text { Before LMA } \\
\text { insertion }\end{array}$} & I $(88.8 \pm 8)$ & \multirow{2}{*}{0.618} & I $(97.3 \pm 9)$ & \multirow{2}{*}{0.072} \\
\hline & II $(87.7 \pm 12)$ & & II $(93.8 \pm 9)$ & \\
\hline \multirow{2}{*}{$\begin{array}{c}2 \text { minutes } \\
\text { after LMA } \\
\text { insertion }\end{array}$} & I $(86.6 \pm 10)$ & \multirow[b]{2}{*}{0.007} & I $(89.1 \pm 6)$ & \multirow[b]{2}{*}{0.319} \\
\hline & II $(81.1 \pm 10)$ & & II (87.4 \pm 9$)$ & \\
\hline \multirow{2}{*}{$\begin{array}{c}5 \text { minutes } \\
\text { after LMA } \\
\text { insertion }\end{array}$} & I $(84.9 \pm 9)$ & \multirow[b]{2}{*}{0.005} & $\mathrm{I}(88.4 \pm 7)$ & \multirow[b]{2}{*}{0.328} \\
\hline & II $(79.1 \pm 10)$ & & II (86.8 \pm 9$)$ & \\
\hline \multirow{2}{*}{$\begin{array}{c}\text { After LMA } \\
\text { removal }\end{array}$} & I (89.1 \pm 11$)$ & \multirow{2}{*}{0.384} & I $(95.0 \pm 10)$ & \multirow{2}{*}{0.467} \\
\hline & II $(90.8 \pm 9)$ & & II $(96.7 \pm 13)$ & \\
\hline
\end{tabular}

Increase in HR was significant at 2 and 5 minutes after the insertion of device in Group I ( $p=0.007$ and 0.005). The mean MAP was comparable in both the groups at all the time ( $p>$ 0.05 ). There was no significant haemodynamic change after removal of device in either group.

\begin{tabular}{|c|c|c|c|c|c|}
\hline \multirow{2}{*}{$\begin{array}{c}\text { Post-Operative } \\
\text { Complications }\end{array}$} & \multicolumn{2}{|c|}{$\begin{array}{c}\text { Group I } \\
\text { (n=50) }\end{array}$} & \multicolumn{2}{c|}{$\begin{array}{c}\text { Group II } \\
\text { (n=50) }\end{array}$} & \multirow{2}{*}{ P-value } \\
\cline { 2 - 5 } & $\mathbf{f}$ & $\mathbf{\%}$ & $\mathbf{f}$ & $\mathbf{\%}$ & \\
\hline $\begin{array}{c}\text { Presence of blood } \\
\text { on LMA }\end{array}$ & 8 & 16 & 0 & 0.0 & 0.010 \\
\hline $\begin{array}{c}\text { Tongue/Lip/Dental } \\
\text { Injury }\end{array}$ & 6 & 12 & 0 & 0.0 & 0.035 \\
\hline Sore throat & 9 & 18.0 & 2 & 4.0 & 0.025 \\
\hline Hoarseness & 9 & 18.0 & 1 & 2.0 & 0.008 \\
\hline \multicolumn{6}{|c|}{ Table VI. Postoperative Complications } \\
\hline
\end{tabular}

As shown in Table VI, on removal of the device Group I had blood stain and tongue/lip/dental injury, while there was no injury noted in any of the patients in Group II $(\mathrm{p}=0.01$, 0.035). Postoperatively, sore throat and immediate hoarseness was comparatively more in Group I ( $p=0.025$, 0.008).

\section{DISCUSSION}

Introduction of supraglottic devices has revolutionised the airway management. Thus, two novel devices, ProSeal LMA and I-gel were compared in this study. The demographic characteristics were comparable in both groups.

The efficacy of the device was determined by its rate of successful placement at first attempt, time taken to insert the device, ease of insertion and quality of airway provided. The success rate of placement at first attempt was higher in Group II ( $p=0.023)$, which was in accordance with previous studies done by Ekinci $O$ et $\mathrm{al}^{7}(\mathrm{p}=0.026)$ and Jadhav PA et $\mathrm{al}^{8}$ $(p<0.05)$. Difficulty in insertion of PLMA may be due to its larger cuff and lack of back plate making cuff more likely to fold over at the back of the mouth. ${ }^{9}$

The time for insertion was considered according to the study conducted by Brimacombe J et al ${ }^{10}$ from picking up the device to confirmation of effective ventilation. In our study, the mean time required for inserting the device was significantly less in Group II $(\mathrm{p}=0.004)$. Consistent with our results, Chauhan $G$ et $\mathrm{al}^{11}(\mathrm{p}=0.001)$ and Kini $\mathrm{G}$ et $\mathrm{al}^{12}(\mathrm{p}=$ 0.001 ) also found similar differences in insertion times with less time required for I-gel insertion. This may be due to additional time required to inflate the cuff of PLMA.

In our study, comparatively significant difference $(p=0.046)$ was observed between the two groups with respect to ease of insertion. This result was similar to the study conducted by Chauhan $\mathrm{G}$ et $\mathrm{al}^{11}(\mathrm{p}=0.0004)$ and Ekinci et $\mathrm{al}^{7}(\mathrm{p}=0.039)$. The ease of insertion in I-gel could be due to the non-inflatable cuff with firm consistency.

The quality of airway was good in both the groups with no significant difference $(\mathrm{p}=0.317)$. Schmidbauer et $\mathrm{al}^{13}$ reported that the PLMA can resist the oesophageal pressure better than the I-gel; however, it applies more pressure on the anatomical structures.

Increase in HR with insertion of PLMA in our study could possibly be due to stimulation of receptors on the wall of the pharynx, resulting in a reflex sympathetic response. Since, Igel is a non-inflatable device, it might have lesser haemodynamic changes. The observations made in this study are in accordance with study results of Jindal $\mathrm{P}$ et al. ${ }^{14}$

As a complication, blood staining and tongue/lip/dental trauma was more in Group I, while none of the Group II patients had any and the difference was highly significant. 
Similar results were found for I-gel by Liew GHC et al ${ }^{15}$ $(p=0.007)$ and Chauhan $G$ et $\mathrm{al}^{11}(p=0.045)$. Singh I et $\mathrm{al}^{16}$ conducted a study which showed that incidence of blood staining of the device was more with LMA-ProSeal $(6 / 30)$ than with I-gel $(1 / 30)$ and tongue, lip and dental trauma was more with LMA-ProSeal $(5 / 30)$ than with I-gel $(1 / 30)$ which was otherwise statistically not significant. Furthermore, postoperative complaints of sore throat and hoarseness of voice were either less evident or not observed in the I-gel group.

The limitation of this study was that the investigators could not be blinded during airway management, hence presenting the possibility of researcher bias.

\section{CONCLUSION}

We conclude that I-gel and PLMA are comparable in terms of good anatomical placement providing adequate ventilation. However, I-gel was more easily inserted at first attempt and in lesser time as compared to PLMA. Also, there are less haemodynamic changes and complications with insertion of I-gel as supraglottic airway device.

\section{REFERENCES}

[1] Hove LD, Steinmetz J, Christoffersen JK, et al. Analysis of deaths related to anesthesia in the period 19962004 from closed claims registrered by the danish patient insurance association. Anesthesiology 2007;106(4):675-80.

[2] Ruetzler K, Krafft P, Frass M. Airway management in intensive care. Chapter 46. Benumof and Hagberg's airway management. $3^{\text {rd }}$ edn. Publisher Saunders and Elsevier 2013:P 953.

[3] Russo SG, Goetze B, Troche S, et al. LMA-ProSeal for elective postoperative care on the intensive care unit: a prospective, randomized trial. Anesthesiology 2009;111(1):116-21.

[4] Cook TM, Lee G, Nolan JP. The ProSeal laryngeal mask airway: a review of the literature. Can J Anesth 2005;52(7):739-60.

[5] Janakiraman C, Chethan DB, Wilkes AR, et al. A randomised crossover trial comparing the I-gel supraglottic airway and classic laryngeal mask airway. Anaesthesia 2009;64(6):674-8.
[6] Levitan RM, Kinkle WC. Initial anatomic investigations of the I-gel airway: a novel supraglottic airway without inflatable cuff. Anaesthesia 2005;60(10):1022-6.

[7] Ekinci O, Abitagaoglu S, Turan G, et al. The comparison of proseal and I-gel laryngeal mask airways in anesthetized adult patients under controlled ventilation. Saudi Med J 2015;36(4):432-6.

[8] Jadhav PA, Dalvi NP, Tendolkar BA. I-gel versus laryngeal mask airway-proseal: comparison of two supraglottic airway devices in short surgical procedures. J Anaesthesiol Clin Pharmacol 2015;31(2):221-5.

[9] Brain AIJ, Verghese C, Strube PJ. The LMA proseal-a laryngeal mask with an oesophageal vent. British Journal of Anaesthesia 2000;84(5):650-4.

[10] Brimacombe J, Keller C, Fullekrug B, et al. A multicenter study comparing the proseal and classic laryngeal mask airway in anesthetized, nonparalyzed patients. Anesthesiology 2002;96(2):289-95.

[11] Chauhan G, Nayar P, Seth A, et al. Comparison of clinical performance of the I-gel with LMA proseal. Journal of Anaesthesiolgy Clinical Pharmacology 2013;29(1):56-60.

[12] Kini G, Devanna GM, Mukkapati KR, et al. Comparison of I-gel with proseal LMA in adult patients undergoing elective surgical procedures under general anesthesia without paralysis: a prospective randomized study. J Anaesthesiol Clin Pharmacol 2014;30(2):183-7.

[13] Schmidbauer W, Bercker S, Volk T, et al. Oesophageal seal of the novel supralaryngeal airway device I-Gel ${ }^{\mathrm{TM}}$ with the laryngeal mask airways classic ${ }^{\mathrm{TM}}$ and proseal $^{\mathrm{TM}}$ using a cadaver model. British Journal of Anaesthesia 2009;102(1):135-9.

[14] Jindal P, Rizvi A, Sharma JP. Is I-gel a new revolution among supraglottic airway devices? MEJ Anesth 2009;20(1):53-8.

[15] Liew GHC, Yu ED, Shah SS, et al. Comparison of the clinical performance of I-gel, LMA Supreme and LMA proseal in elective surgery. Singapore Med J 2016;57(8):432-7.

[16] Singh I, Gupta M, Tandon M. Comparison of clinical performance of I-Gel ${ }^{\mathrm{TM}}$ with LMA-proseal in elective surgeries. Indian J Anaesth 2009;53(3):302-5. 